\title{
Opinion
}

\section{Paediatric Virology and the indisputable value of prevention}

\author{
CHRYSSIE KOUTSAFTIKI $^{1}$, IOANNIS N. MAMMAS ${ }^{2-4}$, ALEXIA PAPATHEODOROPOULOU $^{5}$, \\ EIRINI KOUTSOUNAKI ${ }^{6,7}$, MARIA THEODORIDOU ${ }^{3}$ and DEMETRIOS A. SPANDIDOS ${ }^{2}$ \\ ${ }^{1}$ Paediatric Intensive Care Unit (PICU), 'Penteli' Children's Hospital, 15236 Athens; \\ ${ }^{2}$ Laboratory of Clinical Virology, School of Medicine, University of Crete, 71003 Heraklion; \\ ${ }^{3}$ First Department of Paediatrics, University of Athens School of Medicine, 11527 Athens; \\ ${ }^{4}$ Paediatric Clinic, Aliveri, 34500 Island of Euboea; ${ }^{5}$ Paediatric Intensive Care Unit (PICU), \\ 'Aglaia Kyriakou' Children's Hospital, 11527 Athens; ${ }^{6}$ Neonatal Department, \\ 'Alexandra' Maternity Hospital, 11528 Athens; ${ }^{7}$ Neonatal Department, \\ 'Helena Venizelou' Maternity Hospital, 11521 Athens, Greece
}

Received July 22, 2019; Accepted August 26, 2019

DOI: $10.3892 /$ etm.2019.7954

'Prevention is better than cure'

Hippocrates

Hippocrates' famous apothegm 'prevention is better than

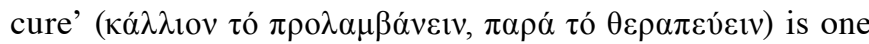
of the most valuable principles of Paediatrics, providing the milestone of all immunisation strategies currently used in neonates, children and adolescents (1). To date, the indisputable value of prevention has been highlighted in all 'workshops on Paediatric Virology' (2-6). Table I presents the titles of all plenary lectures, oral and poster presentations, which were performed during the workshops, focusing on the value of prevention in the management of neonatal and paediatric viral infections. Along with the significant role of human breast milk in the prevention of viral infections during the first years of life (7) and prophylaxis against respiratory syncytial virus (RSV) $(8,9)$, the examined prevention issues included the 60-year-old battle against poliomyelitis (10), the vaccination against hepatitis $\mathrm{B}$ in newborns (11-13), the vaccination challenges against human papillomaviruses (HPV) (14-19), the vaccination against mumps, measles and rubella (20), the prevention against influenza including the role of the intranasal live-attenuated influenza vaccines (21-25), the necessity

Correspondence to: Professor Demetrios A. Spandidos, Laboratory of Clinical Virology, School of Medicine, University of Crete, 71003 Heraklion, Greece

E-mail: spandidos@spandidos.gr

Key words: Paediatric Virology, prevention, viral infections, breast feeding, premature neonates, immigration crisis, hepatitis B, human papillomavirus, influenza, anti-vaccination movement to implement a vaccination policy in relation to immigration effects (26), the preventative role of probiotics in the management of viral infections in children $(27,28)$, the emerging need for the establishment of prevention strategies against Ebola virus (29) and the overview of the anti-vaccination movement (30).

Interestingly, during the ' 3 rd workshop on Paediatric Virology', which was held in Athens (Greece) on October 7th, 2017, the statements by the Nobelist Laureate Professor of Virology Harald zur Hausen (Heidelberg, Germany) on the significant preventative role of breast feeding and the mandatory necessity of male vaccination against HPV (4) attracted the enormous interest of paediatric trainees and junior paediatricians. In the recent '5th workshop on Paediatric Virology', which will take place in Sparta (Greece) on October 12th, 2019, the top key messages of four out of five plenary lectures will also highlight the value and the need of specific prevention strategies and recommendations against RSV in infancy and childhood (Table II). As future therapeutic options and strategies are expected with impatience, prevention remains the principal tool for the management of neonatal and paediatric viral infections.

\section{Acknowledgements}

This article is published in the third supplement issue of the Experimental and Therapeutic Medicine, which is dedicated to Paediatric Virology. This edition is performed in the context of the '5th workshop on Paediatric Virology' (Sparta, Greece, October 12, 2019) organized by the Paediatric Virology Study Group (PVSG) and supported by the Department of Clinical Virology of the University of Crete School of Medicine and the First Department of Paediatrics of the University of Athens School of Medicine. We would 
Table I. Plenary lectures, oral presentations and posters of the 'workshops on Paediatric Virology' during the 2015-2018 period highlighting the value of prevention in Paediatric Virology.

Speaker/presenter

Title of presentation

1st workshop on Paediatric Virology (2015)

Professor Anne Greenough (United Kingdom)

The impact of viral infections on the long-term outcomes of prematurely born infants

Professor Maria Theodoridou (Greece)

Defeating polio: Vaccine anniversary (1955-2015)

Professor Anna Kramvis (South Africa)

The clinical implications of hepatitis B virus genotypes in Paediatrics

Dr Ioannis N. Mammas (Greece)

Understanding the factors affecting human papillomavirus vaccination acceptance among adolescents

Dr Maria Koutsaki (Greece)

Dr Iliana Christaki (United Kingdom)

MMR vaccination and autism

The challenge of modern biowarfare: ED preparedness for paediatric victims of the Ebola virus

2nd workshop on Paediatric Virology (2016)

Professor Maria Theodoridou (Greece)

Professor Anna Kramvis (South Africa)

Dr Prakash Thiagarajan (British Isles)

Dr Sharryn Gardner (United Kingdom)

Professor Angeliki Melidou (Greece)

Dr Chryssie Koutsaftiki (Greece)
The Greek experience of HIV-1 infection in children

Hepatitis B vaccination in Africa: Current situation and future challenges

Zika Virus in pregnancy and infancy - What do the paediatricians need to know?

It's never just a virus - Experiences from the frontline

Influenza in childhood: A usual suspect

The antivaccination movement: A brief historical overview

3rd workshop on Paediatric Virology (2017)

Professor Harald zur Hausen (Germany)

Professor Anne Greenough (United Kingdom)

Professor Anna Kramvis (South Africa)

Professor Maria Theodoridou (Greece)

Dr Maria Rusan (USA)

Professor Angeliki Melidou (Greece)

Dr Paraskevi Korovessi (Greece)

4th workshop on Paediatric Virology (2018)

Professor Tina Dalianis (Sweeden)

Dr Prakash Thiagarajan (British Isles)

Professor Maria Theodoridou (Greece)

Professor Angeliki Melidou (Greece)

Dr Paraskevi Korovessi (Greece)

Dr Chryssie Koutsaftiki (Greece)

Dr Ioannis N. Mammas (Greece)

Professor Apostolos Zaravinos (Cyprus)

Dr Sotirios Doukas (USA)
Paediatric Virology and Oncology: Virus persistence and the important first years of life

The long-term impact of viral infections on prematurely born infants

Mother-to-child transmission of hepatitis B and C viruses

Immigration crisis and vaccination policy

Human papillomavirus infections in children: Should we be vaccinating earlier?

Intranasal live-attenuated influenza vaccination in children: Evidence, limitations and proposals

Probiotics and viral infections in childhood
Human papillomavirus (HPV) prevalence in youth at a youth clinic after the initiation of HPV-catch up vaccination in comparison to previously obtained HPV prevalence in the same clinic and to that in high school in youth Sweden

Antiviral drugs in the clinical management of children with influenza

Overview of influenza vaccination in children

Epidemiology of influenza types and subtypes in childhood

Prevention and management of influenza in childhood: The effect of probiotics

Participation of paediatric health professionals into the vaccination programme against seasonal influenza

Exploring effective interventions to increase adolescents' vaccination against human papillomavirus (HPV)

HPV as an emerging risk factor in head and neck carcinomas: An additional vaccination target?

Laryngeal HPV infection in children: A review of management and treatment of Juvenile Onset Recurrent Respiratory Papillomatosis 
Table II. Plenary lectures of the '5th workshop on Paediatric Virology', which will be held in Sparta on October, 12, 2019, highlighting the value of prevention in Paediatric Virology.

Speaker/presenter

Professor Simon B. Drysdale (United Kingdom) Professor Barbara Rath (Germany)

Professor Maria Theodoridou (Greece) Professor George P. Chrousos (Greece)
Title of presentation
Management of RSV infection in children: New advances and challenges Understanding the burden of RSV and influenza infections in real-time: Partnering for Enhanced Digital Surveillance of Influenza-Like Disease and the Effectiveness of Antivirals and Vaccines (PEDSIDEA)

Prevention of RSV infections: What is new with the vaccines?

Viral infections and stress like to thank all the members of the PVSG for their valuable comments and corrections.

\section{References}

1. Mammas IN and Spandidos DA: Paediatric Virology in the Hippocratic Corpus. Exp Ther Med 12: 541-549, 2016.

2. Mammas IN, Greenough A, Theodoridou M, Kramvis A, Christaki I, Koutsaftiki C, Koutsaki M, Portaliou DM, Kostagianni G, Panagopoulou P, et al: Current views and advances on Paediatric Virology: An update for paediatric trainees. Exp Ther Med 11: 6-14, 2016.

3. Mammas IN, Theodoridou M, Kramvis A, Thiagarajan P, Gardner S, Papaioannou G, Melidou A, Koutsaki M, Kostagianni G, Achtsidis V, et al: Paediatric Virology: A rapidly increasing educational challenge. Exp Ther Med 13: 364-377, 2017.

4. Mammas IN, Greenough A, Theodoridou M, Kramvis A, Rusan M, Melidou A, Korovessi P, Papaioannou G, Papatheodoropoulou A, Koutsaftiki C, et al: Paediatric Virology and its interaction between basic science and clinical practice (Review). Int J Mol Med 41: 1165-1176, 2018.

5. Mammas IN, Theodoridou M, Thiagarajan $P$, Melidou A, Papaioannou G, Korovessi P, Koutsaftiki C, Papatheodoropoulou A, Calachanis M, Dalianis T, et al: A paediatric influenza update 100 years after the Skyros island Spanish flu outbreak. Exp Ther Med 17: 4327-4336, 2019.

6. Mammas IN, Dalianis T, Doukas SG, Zaravinos A, Achtsidis V, Thiagarajan P, Theodoridou M and Spandidos DA: Paediatric virology and human papillomaviruses: An update. Exp Ther Med 17: 4337-4343, 2019.

7. zur Hausen H: Paediatric Virology and Oncology: Virus persistence and the important first years of life. Int J Mol Med 40: S41, 2017.

8. Greenough A, Drysdale S, Broughton S and Bont L: The impact of viral infections on the long-term outcomes of prematurely born infants. Int J Mol Med 36: S89, 2015.

9. Greenough A, MacBean V, Lunt A, Drysdale SB, Rafferty GF and Peacock JL: The long term impact of viral infections on prematurely born infants. Int J Mol Med 40: S41, 2017.

10. Theodoridou M: Defeating polio: Vaccine anniversary (1955-2015). Int J Mol Med 36: S89, 2015.

11. Kramvis A: The clinical implications of hepatitis B virus genotypes in Paediatrics. Int J Mol Med 36: S89, 2015.

12. Kramvis A and Kew MC: Epidemiology of hepatitis B virus in Africa, its genotypes and clinical associations of genotypes. Hepatol Res 37 (s1): S9-S19, 2007.

13. Kramvis A: Mother to child transmission of hepatitis B and C viruses. Int J Mol Med 40: S39, 2017.
14. Grün N, Du J, Ährlund-Richter A, Mirzaie L, Ramqvist T and Dalianis T: Human papillomavirus (HPV) prevalence in youth at a youth clinic after the initiation of HPV-catch up vaccination in comparison to previously obtained HPV prevalence in the same clinic and to that in high school youth in Sweden. Int J Mol Med 42: S16, 2018.

15. Mammas IN, Sourvinos G, Theodoridou M and Spandidos DA: Understanding the factors affecting human papillomavirus vaccination acceptance among adolescents. Int J Mol Med 36: S90, 2015.

16. Mammas IN, Theodoridou M, Sourvinos G and Spandidos DA: Exploring effective interventions to increase adolescents' vaccination against human papillomavirus (HPV). Int J Mol Med 42: S17, 2018.

17. Rusan M: Human papillomavirus infections in children: Should we be vaccinating earlier? Int J Mol Med 40: S40, 2017.

18. Zaravinos A: HPV as an emerging risk factor in head and neck carcinomas: An additional vaccination target? Int J Mol Med 42: S40, 2018.

19. Doukas SG: Laryngeal HPV infection in children: A review of management and treatment of Juvenile Onset Recurrent Respiratory Papillomatosis. Int J Mol Med 42: S17, 2018.

20. Koutsaki M: MMR vaccination and autism: An update. Int J Mol Med 36: S91, 2015.

21. Theodoridou M: Overview of influenza vaccination in children. Int J Mol Med 42: S17, 2018.

22. Melidou A: Influenza in childhood: A usual suspect. Int J Mol Med 38: S66, 2016.

23. Melidou A: Intranasal live-attenuated influenza vaccination in children: Evidence, limitations and proposals. Int J Mol Med 40: S39, 2017.

24. Melidou A: Epidemiology of influenza types and subtypes in childhood. Int J Mol Med 42: S18, 2018.

25. Koutsaftiki C and Papatheodoropoulou A: Participation of paediatric health professionals into the vaccination programme against seasonal influenza. Int J Mol Med 42: S18, 2018.

26. Theodoridou M: Immigration crisis and vaccination policy. Int $\mathrm{J}$ Mol Med 40: S41, 2017.

27. Korovessi P: Probiotics and viral infections in childhood. Int $\mathbf{J}$ Mol Med 40: S39, 2017.

28. Korovessi P: Prevention and management of influenza in childhood: The effect of probiotics. Int J Mol Med 42: S37, 2018.

29. Christaki I, Beattie T and Midgley P: The challenge of modern biowarfare: ED preparedness for paediatric victims of the Ebola virus. Int J Mol Med 36: S90, 2015.

30. Koutsaftiki C: The antivaccination movement: A brief historical overview. Int J Mol Med 38: S67, 2016.

This work is licensed under a Creative Commons Attribution-NonCommercial-NoDerivatives 4.0 International (CC BY-NC-ND 4.0) License. 